\title{
Síndrome de Rett
}

\section{Rett syndrome}

\author{
José Salomão Schwartzman \\ Programa de Pós-graduação em Distúrbios do Desenvolvimento da Universidade Presbiteriana Mackenzie. São Paulo, SP, Brasil
}

Resumo A partir do que já se conhece sobre a síndrome de Rett, este artigo focaliza as informações mais recentes da literatura internacional sobre os aspectos genéticos e etiológicos desta condição, bem como sobre a sua identificação clínica e laboratorial, neuropatologia, eletrofisiologia, e evolução clínica (epilepsia, distúrbios respiratórios, distúrbios autonômicos e aspectos nutricionais), enfatizando, ainda, que, embora até recentemente tida como condição que afetava apenas o sexo feminino, também pode estar presente no sexo masculino, ainda que com fenótipo diverso.

Descritores Síndrome de Rett. Deficiência mental. Deficiência múltipla. Epilepsia. Genética clínica.

Abstract This article is focus on the currently knowledge about Rett syndrome, based on the more recent information in the international literature on genetic and epidemiological aspects of this condition, as well as on its clinical and laboratory diagnosis, neuropathology, electrophysiology. and clinical outcome (epilepsy, respiratory disorders, autonomic disturbances and nutritional aspects). Although it has been known as a female condition, nowadays it is described the possibility of affected males with a different phenotype.

Keywords Rett syndrome. Mental retardation. Multiple handicap. Epilepsy. Clinical genetics.

\section{Introdução}

Andreas Rett ${ }^{1}$ identificou, em 1966, uma condição caracterizada por deterioração neuromotora em crianças do sexo feminino, quadro clínico bastante singular, acompanhado por hiperamonemia, tendo-o descrito como uma "Atrofia Cerebral Associada à Hiperamonemia".

A condição por ele descrita somente passou a ser melhor conhecida após a publicação do trabalho de Hagberg et $\mathrm{al},{ }^{2}$ no qual foram descritas 35 meninas, e a partir do qual foi sugerido o epônimo de síndrome de Rett (SR). A presença da hiperamonemia não foi confirmada como um sinal habitual da síndrome. Admite-se, na atualidade, uma prevalência da doença estimada entre 1:10.000 e 1:15.000 meninas, ${ }^{2}$ sendo uma das causas mais frequientes de deficiência mental severa que afeta o sexo feminino.

No Brasil, a SR foi inicialmente identificada por Rosemberg et $\mathrm{al}^{3,4}(1986,1987)$.

Desde então, vários trabalhos foram publicados no Brasil, ${ }^{5-7}$ divulgando o quadro clínico e tornando possível a identificação de algumas centenas de meninas afetadas.

Para o diagnóstico clínico da SR podem ser utilizados os crité- rios definidos pelo Rett Syndrome Diagnostic Criteria Work Group ${ }^{8}$ (1988) ou os propostos pelo DSM-IV-R ${ }^{9}$ (2002) (Tabela).

$\mathrm{O}$ diagnóstico da $\mathrm{SR}$, até pouco tempo, era exclusivamente clínico, existindo ainda critérios para o diagnóstico de quadros atípicos da SR, ${ }^{10}$ que somente devem ser firmados após os 10 anos de idade. Na atualidade, a descrição de uma alteração genética identificável em aproximadamente $80 \%$ dos casos (ver a seguir) sugere que esse recurso deva ser utilizado na elaboração final do diagnóstico.

\section{Quadro clínico}

A doença evolui de forma previsível, em estágios, que foram nomeados por Hagberg \& Witt-Engerström ${ }^{11}$ (1986) da seguinte forma: o primeiro deles, denominado estagnação precoce, inicia-se entre seis e 18 meses e caracteriza-se por uma parada no desenvolvimento, desaceleração do crescimento do perímetro craniano, diminuição da interação social com conseqüente isolamento. Esse estágio tem a duração de alguns meses.

$\mathrm{O}$ segundo, rapidamente destrutivo, inicia-se entre um e três anos de idade e tem a duração de semanas ou meses. 
Tabela - Critérios diagnósticos para Transtorno de Rett (299.80).

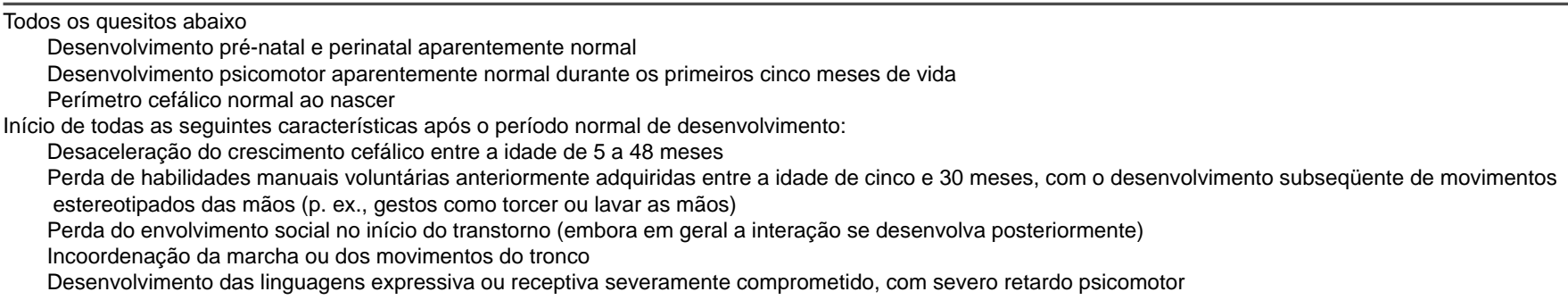

Uma rápida regressão psicomotora domina o quadro, com a presença de choro imotivado e períodos de extrema irritabilidade, comportamento tipo autista, perda da fala e aparecimento dos movimentos estereotipados das mãos, com subseqüente perda da sua função práxica; disfunções respiratórias (apnéias em vigília, episódios de hiperventilação e outras) e crises convulsivas começam a se manifestar. Em algumas crianças há perda da fala que já estava eventualmente presente. Distúrbios do sono são comuns.

Entre os dois e dez anos de idade instala-se o terceiro estágio: o pseudo-estacionário, no qual ocorre certa melhora de alguns dos sinais e sintomas, inclusive do contato social. Os distúrbios motores são evidentes, com presença de ataxia e apraxia, espasticidade, escoliose e bruxismo. Os trabalhos estrangeiros referem que nessa fase é muito comum ocorrer perda de peso, apesar de ingesta normal. Todavia, em pesquisa conduzida no Brasil, Schwartzman ${ }^{12}$ não encontrou desnutrição entre as crianças examinadas. Ao contrário do que se poderia esperar, várias das pacientes apresentavam sobrepeso. Crises de perda de fôlego, aerofagia e expulsão forçada de ar e saliva ocorrem com freqüência.

O quarto estágio, que se inicia por volta dos dez anos de idade, é o da deterioração motora tardia, ocorrendo lenta progressão dos déficits motores, com presença de escoliose e severa deficiência mental. Epilepsia pode se tornar menos importante, e as poucas pacientes que ainda retêm a deambulação gradualmente terão prejuízos crescentes, acabando por ter que utilizar cadeiras de rodas. Observa-se, nesse período, a superposição de sinais e sintomas decorrentes de lesão do neurônio motor periférico aos prejuízos já presentes. Presença de coreo-atetose é comum nessa fase.

Apesar de ser habitual afirmar-se que as meninas com SR são normais ao nascimento e demonstram um desenvolvimento normal até os seis ou dezoito meses de idade, sabe-se hoje que em grande parte dos casos, senão em todos, há na verdade um atraso no desenvolvimento motor com hipotonia muscular e prejuízo no engatinhar, que são os sinais iniciais. ${ }^{13}$

A fala está sempre muito comprometida e, muitas vezes, totalmente ausente. Algumas crianças chegam a falar, deixando de fazê-lo à medida que a deterioração avança. Algumas poucas adquirem alguns vocábulos isolados. Apenas um trabalho refere a presença de "frases apropriadas" em casos de SR.${ }^{14}$ Estudo que se baseou no exame de uma amostra composta por 265 pacientes com quadros clássicos e atípicos de SR e pôde comprovar que, $30 \%$ delas nunca desenvolveram palavras inteligíveis, 55\% deixaram de falar após ter adquirido fala, $15 \%$ retinham algumas palavras e $6 \%$ do total continuavam a fazer uso apropriado de frases.

Crises epilépticas são de ocorrência comum. Podem assumir várias formas e, eventualmente, demonstrar grande resistência à medicação antiepiléptica habitual. Afirmar a real prevalência de epilepsia nessas pacientes é difícil, porque elas podem apresentar outras manifestações paroxísticas que são, muito freqüentemente, confundidas com epilepsia. Hagberg et al, ${ }^{15}$ por exemplo, afirmam que nas séries por eles acompanhadas, a ocorrência de epilepsia pôde ser comprovada em $94 \%$ dos casos. A média de idade da população era de 20 anos, variando entre quatro e 58 anos. Freqüentemente crises de perda de fôlego, crises hipoxêmicas seguindo episódios de apnéia são diagnosticadas erroneamente como epilepsia, o que pode contribuir para prevalências superestimadas de epilepsia nessas crianças. ${ }^{5}$

O eletroencefalograma é, em geral, grosseiramente anormal, exceção feita, eventualmente, às primeiras fases da doença. À medida que a condição evolui do estágio I para o III, observaremos lentificação progressiva do ritmo de base com surgimento de ondas pontiagudas projetando-se, em geral, nas regiões centro-parietais. No estágio III podem surgir descargas com o padrão espícula-onda lenta, mais facilmente observada durante o sono. No estágio IV pode haver uma certa melhora no traçado com diminuição dos elementos epileptiformes. As espículas centrais tendem a diminuir após os dez anos de idade e podem ser bloqueadas pela movimentação passiva dos dedos da mão contralateral. ${ }^{16}$

A sobrevida na SR pode ser limitada, sobrevindo a morte, em geral, em decorrência de um quadro infeccioso ou durante o sono (morte súbita). Outro fator que pode limitar tanto a qualidade de vida como o tempo de sobrevida, consiste nos problemas respiratórios crônicos decorrentes de problemas secundários à escoliose, que pode chegar a comprometer seriamente a expansão pulmonar.

No quadro clínico da SR podemos observar algumas alterações que permitem supor algum tipo de disfunção autonômica. Julu et $\mathrm{al}^{17}$ estudaram, sob este ponto de vista, 17 meninas com a SR. Demonstraram que o tono vagal cardíaco era $65 \%$ inferior ao de meninas controles. Esses valores são similares aos observados em recém-nascidos normais. Cada uma das meninas Rett apresentou, pelo menos, seis alterações no ritmo respiratório. O tono vagal cardíaco era suprimido no ápice da atividade simpática, tanto durante os 
períodos de hiperventilação, quanto nos de perda de fôlego, levando a um desequilíbrio com risco de arritmias cardíacas e possivelmente morte súbita.

\section{Genética}

A grande maioria dos casos de SR é composta de casos isolados dentro de uma família, exceção feita à ocorrência em irmãs gêmeas; porém, casos familiares têm sido observados. Costumava-se considerar a SR como uma desordem dominante ligada ao cromossomo $\mathrm{X}$, em que cada caso representaria uma mutação fresca, com letalidade no sexo masculino. Foram observados casos nos quais meninos, irmãos de meninas com a SR, nasciam com uma doença encefalopática com óbito precoce. ${ }^{18}$

Nessa perspectiva, alguns poucos casos foram descritos nos quais um fenótipo similar ao da SR foi observado em meninos. ${ }^{18-21}$ Em geral, constituíam apenas um sugestivo do diagnóstico, com sinais e sintomas presentes de forma bastante atípica e parcial.

Em 1998, ${ }^{22}$ foi descrito um caso de um menino que, na ocasião, tinha dois anos e nove meses de idade, apresentando fenótipo integral da SR na sua forma clássica. Esse menino, apresenta cariótipo XXY, caracterizando, portanto, uma associação das síndromes de Klinefelter com a SR, ocorrência com uma probabilidade da ordem de uma para dez a $15 \mathrm{mi}-$ lhões de nascimentos.

Apenas um ano após, em 1999, foram descritas pela primeira vez mutações no gene $\mathrm{MeCP} 2$ em pacientes com a SR. ${ }^{23,24}$

Interessante que após a descrição dessas mutações do MECP2, foi realizada a pesquisa para esse marcador no menino anteriormente referido, no qual havia sido descrita a associação do fenótipo Rett e XXY. Foi encontrada uma mutação nesse gene, confirmando tratar-se, realmente, da SR. ${ }^{25}$

Estudos mais recentes indicam que cerca de $75 \%$ a $80 \%$ de pacientes com a forma clássica da SR têm mutações no gene MECP $2 .{ }^{26}$ Considera-se que a proteína MeCP2, produzida pelo gene, funciona como repressor global de transcrição. Como essa proteína possui alguns diferentes sítios de ação, acreditase que as diferentes mutações encontradas no gene seriam responsáveis pelos diferentes fenótipos observados nos portadores de SR. ${ }^{27}$ Sabemos, hoje, que alguns meninos portadores das mesmas mutações podem sobreviver, apresentando um quadro encefalopático totalmente distinto do quadro clínico clássico da SR no sexo feminino. ${ }^{28}$ Também se aceita que a pesquisa de mutações no gene MECP2 esteja justificada em meninos com formas severas de encefalopatia que não tenham alguma etiologia claramente definida.

\section{Patologia}

Do ponto de vista neuropatológico, é fato a desaceleração do crescimento craniano que ocorre a partir do terceiro mês. O lobo frontal, o núcleo caudado e o mesencéfalo são as regiões encefálicas nas quais foram observadas as maiores reduções. Começam a surgir evidências de que a SR poderia estar relacionada a uma deficiência pós-natal no desenvolvimento das sinapses; mas restaria, ainda, conhecer o defeito básico presente. ${ }^{29}$

Com o conhecimento da mutação encontrada no gene MECP2, um grupo de pesquisadores do Texas produziu um camundongo transgênico com uma mutação truncada no gene MECP2 $2{ }^{27}$ Os animais não aparentam anormalidades até aproximadamente a sexta semana, quando surge um tremor ao erguer-se o animal pela cauda. Após oito meses, alterações na pelagem, presença de convulsões e mioclonias podem ser observadas. Interessante que, após essa idade, o animal produz uma série de movimentos estereotipados das patas dianteiras quando suspenso pela cauda. O mecanismo pelo qual a alteração desse gene parece determinar o fenótipo do quadro ainda não está completamente compreendido. Porém, observou-se que, nesses animais, um aumento da acetilação de um grupo de histonas, comprometendo a arquitetura da cromatina em determinadas regiões cerebrais, principalmente do córtex e do cerebelo. Conseqüência desse processo poderia ser uma maior acessibilidade do DNA por diferentes fatores transcricionais, o que implicaria na interferência da expressão de diversos genes. Os estudos agora procuram compreender quais seriam os diferentes genes que estariam desregulados pela ação dessa alteração da proteína MeCP2.

\section{Diagnóstico diferencial}

Dependendo da fase em que se encontra a SR, várias condições deverão ser levadas em consideração entre os diagnósticos diferenciais: patologias fixas, como a paralisia cerebral e outras encefalopatias fixas; síndrome de Angelman; autismo infantil; e várias doenças metabólicas (por ex. lipofuccionoses).

\section{Conclusão}

A síndrome de Rett é uma das causas mais freqüentes de deficiência múltipla severa no sexo feminino. Pelo conjunto de suas características, trata-se de quadro que deve interessar todos os profissionais da área da saúde, especialmente pediatras, para o encaminhamento e diagnóstico precoce, e especialistas que atendam pessoas com distúrbios neuropsiquiátricos severos.

\section{Referências}

1. Rett A. Úber ein elgenartiges hirnatrophisches syndrom bei Hyperammonamie in Kindesalter. Wein Med Wochenschr 1966;116:723-6.

2. Hagberg B, Aicardi J, Dias K, Ramos O. A progressive syndrome of autism, dementia, ataxia, and loss of purposeful hand use in girls: Rett's syndrome: report of 35 cases. Ann Neurol 1983;14:471-9.

3. Rosemberg GS, Arita FN, Campos C. A Brazilian girl with the Rett syndrome. Brain Dev 1986;8:554-6.

4. Rosemberg GS, Arita F, Campos C, Coimbra AR, Ellovitch S, Geres S. Síndrome de Rett: análise dos primeiros cinco casos diagnosticados no Brasil. Arq Neuropsiquiat 1987;45:143-58.

5. Schwartzman JS. Síndrome de Rett. Temas sobre Desenvolvimento 1990;1:8-1. 
6. Pereira JLP A síndrome de Rett: uma introdução ao seu diagnóstico clínico, diagnóstico diferencial e ao planejamento de ações de reabilitação. Curitiba: Departamento de Educação Especial da Secretaria de Estado da Educação do Paraná; 1992. p. 25.

7. Santos S, Sá AMRF, Dagnesi MD, Maletta PM, Andrade RLP, Marchioni SAE, et al. O perfil da portadora de síndrome de Rett no Brasil. Temas sobre Desenvolvimento 1999;45:6-12.

8. The Rett Syndrome Diagnostic Criteria Work Group. Diagnostic Criteria for Rett Syndrome. Ann Neurol 1988;23:425-8.

9. Associação Americana de Psiquiatria. Manual diagnóstico e estatístico de transtornos mentais - DSM-IV-TR. $4^{\mathrm{a}}$ ed. Dornelles C, tradutora. Porto Alegre: Artmed; 2002.

10. Hagberg B, Skjeldal $\mathrm{OH}$. Rett variants: a suggested model for inclusion criteria. Pediatr Neurol 1994;11:5-11

11. Hagberg B, Witt-Engerström J. Rett syndrome: a suggested staging system for describing impairment profile with increasing age towards adolescence. Am J Med Genet 1986;24:47-59.

12. Schwartzman F. Avaliação nutricional, consumo e práticas alimentares, prevalência de constipação intestinal e anemia em pacientes com síndrome e Rett [Tese de mestrado]. São Paulo: Departamento de Nutrição da Universidade Federal de São Paulo; 2000.

13. Nomura Y, Segawa M. Clinical features of the early stage of the Rett syndrome. Brain Dev 1990;12:16-9.

14. Kerr AM, Belichenko P, Woodcock T, Woodcock M. Mind and brain in Rett disorder. Brain Dev 2001;23:S44-S9.

15. Hagberg B, Berg M, Steffenburg U. Three decades of sociomedical experiences from West Swedish Rett females 4-60 years of age. Brain Dev 2001;23:S28-31

16. Dunn HG. Importance of Rett syndrome in child neurology. Brain Dev 2001;23:538-43.

17. Julu PO, Kerr AM, Hansen S, Apartopoulos F, Jamal GA. Immaturity of medullary cardiorespiratory neurones leading to inappropriate autonomic reactions as a likely cause of sudden death in Rett's syndrome. Arch Dis Child 1997;77:464-5.

18. Coleman M. Is classical Rett syndrome ever present in males? Brain Dev $1990 ; 12: 31-2$
19. Eeg-Olofsson O, Al-Zuhair AGH, Teebi AS, Zaki M, Daoud AS. A boy with the Rett syndrome? Brain Dev 1990;12:529-32.

20. Philippart M. The Rett syndrome in males. Brain Dev 1990;12:33-6.

21. Topçu M, Topaglu H, Renda Y, Berket M, Turanl, G. The Rett syndrome in males. Brain Dev 1991;13:62

22. Schwartzman, JS, Souza AM, Faiwichow G, Hercowitz LH. Fenótipo Rett em paciente com cariótipo XXY. Arq Neuropsiquiat 1998;56:824-8.

23. Amir RE, Van den Veyver IB, Wan M, Tran CQ, Francke U, Zoghbi HY Rett syndrome is caused by mutations in X-linked MECP2, encoding methyl-CpG-binding protein 2. Nat Genet 1999;23:185-8.

24. Wan M, Lee SS, Zhang X, Houwink-Manville I, Song HR, Amir RE, et al Rett syndrome and beyond:recurrent spontaneous and familial MECP2 mutations at CpG hotspots. Am J Hum Genet 1999;65:1520-9.

25. Schwartzman JS, Bernardino A, Nishimura A, Gomes RR, Zatz M. Rett syndrome in a boy with a 47,XXY karyotype confirmed by a rare mutation in the MECP2 gene. Neuropediatrics 2001;32:162-4.

26. Huppke P, Laccome F, Krämer N, Engel W, Hanefeld F. Rett syndrome: analysis of MeCP2 and clinical characterization of 31 patients. Hum Mol Genet 2000;9:1369-75.

27. Shahbazian MD, Young JI, Yuva-Paylor LA, Spencer CM, Antalffy BA, Noebels JL, et al. Mice with truncated MeCP2 recapitulate many Rett Syndrome features and display hyperacetylation of histone H3. Neuron 2002;35:243-54

28. Dotti MT, Orrico A, De Stefano N, Battisti C, Sicurelli F, Severi S, et al. A Rett syndrome MECP2 mutation that causes mental retardation in men. Neurology 2002;58:226-30.

29. Belichenko PV, Hagberg B, Dahlström A. Morphological study of neocortical areas in Rett syndrome. Acta Neuropathol 1997;93:50-61.

\section{Correspondência:}

José Salomão Schwartzman

Praça Dr. Carvalho Franco, 67 Vila Mariana

04019-060 São Paulo, SP, Brasil

Tel./fax: (0xx11) 5571-7743

E-mail: josess@terra.com.br 